THE WABASH CENTER

JOURNAL on TEACHING

\title{
Enhancing Education and Training Initiatives Through Serious Games
}

\author{
John Denholm and Linda Lee-Davies \\ Hershey, PA: IGI Global, 2017 (xiv + 311 pages, ISBN 978-1522536895, \$148.00)
}

\author{
Reviewed By \\ Emily Kahm \\ College of St. Mary
}

Enhancing Education and Training Initiatives Through Serious Games by John Denholm and Linda Lee-Davies is a highly technical, theoretically-oriented text that outlines both the justification for and best use of games or simulation activities as learning experiences. Its eight chapters lay out the research and vocabulary of educational games, explore their design and development, and offer examples from business courses with commentary on their uses. Because of the specialized, and often difficult, language and the business backdrop of the authors, theological educators are likely to find only chapters one, four, five, and six to be relevant and should expect to do significant critical reflection in order to translate the concepts and examples into games or simulations that would suit undergraduate or graduate students in religion or theology.

The authors, both based at the University of Manchester, UK, come from commercial and academic backgrounds; Denholm is in engineering and Lee-Davies is in business and leadership. The diversity of their experiences likely informs the central premise of the book-that games or simulation activities, properly used, are effective means of teaching relevant theoretical material, not just the "soft skills" of communication and teamwork. Educators who have used unorthodox projects in academic courses can attest to how well unique, experiential learning enhances students' retention of material.

Theological educators may gain some useful reflective material from the sections where the authors address interactivity in learning contexts broadly, such as Chapter 4, "Academic Training." The authors provide exhaustive points to consider when aiming for a more collaborative style of classroom, including the technological norms of one's particular generation and the generation of students, the social structure of a classroom and power dynamics, and the level of competition or cooperation students feel as a group. While the text does not go so far as to specify how an instructor might shape each aspect of their classroom culture, readers will certainly gain a new set of questions to ponder about the cultures they create through their teaching style and whether those standards encourage or discourage shared learning.

While the text is well-researched and addresses an important aspect of pedagogical techniques, it is not necessary for theological educators to read it in its entirety, primarily because the mismatch of disciplines puts readers in the position of reimagining nearly every aspect of game structure the authors introduce. This challenge might prove invigorating for those who are especially attuned to the intricacies of the theories that undergird the text, but readers should expect to gain the most from the more broadly framed portions while noting that the examples, though engaging, will not provide a template for game-based instruction in a theological context. Most theological educators are likely to prefer a more introductory book for expanding their repertoire of teaching skills. This text is ultimately only suited for theological educators who are prepared for the demanding task of translating the specialized language used by these authors into their own pedagogical framework. 